\title{
Absolute Neutrophil Count as a Septic Shock Predictor in Pediatric Emergency Room
}

\author{
Lucy Amelia*, Idham Jaya Ganda, Dasril Daud \\ Department of Pediatrics, Medical Faculty of Hasanuddin University, Makassar, South Sulawesi, Indonesia \\ Email address: \\ ameliasisie@gmail.com (L.Amelia),dhamjaya_spa@yahoo.co.id (I. J. Ganda),drdasri@gmail.com (D. Daud)
}

To cite this article:

Lucy Amelia, Idham Jaya Ganda, Dasril Daud. Absolute Neutrophil Count as a Septic Shock Predictor in Pediatric Emergency Room. American Journal of Clinical and Experimental Medicine. Vol. 3, No. 2, 2015, pp. 68-72. doi: 10.11648/j.ajcem.20150302.14

\begin{abstract}
Introduction: The Absolute Neutrophil Count (ANC) is a neutrophil percentage multiplied by the total leukocytes in blood. Its use as a prognostic indicator has been studied in a variety of circumstances, especially sepsis in the neonates and children. Objective: This research aims to investigate the roles of the ANC as the predictor of the septic shock. Methods: It was a prospective cohort study. The data were collected when the patients were brought into the Pediatric Emergency Room (PER) of Dr. Wahidin Sudirohusodo Hospital, Makassar in September through December 2012. The ANC total of the treated patients was counted and then the patients were put into two groups: the group with $\mathrm{ANC}<1500 / \mathrm{mm} 3$ and the group with ANC $\geq$ $1500 / \mathrm{mm} 3$. The individual health condition of each ANC group was observed carefully in order to determine whether the patients suffered from the septic shock or not. Results: The incidence of the septic shock in the ANC group of $<1500 / \mathrm{mm} 3$ was greater compared to that of $\geq 1500 / \mathrm{mm} 3$ with the $\mathrm{p}$ value $=0.015(\mathrm{p}<0.05)$. Besides, it was found that the odds ratio $=$ $6.333, \mathrm{CI}=95 \%(1.523-26.335)$. No significant differences of septic shock incidence were found between age, nutritional status, sex and infectious/non infectious disease. Conclusion: The mean value of the ANC in patients with septic shock is lower compared with non septic shock. The incidence of septic shock in patients with ANC $\geq 1500 / \mathrm{mm} 3$ group; ANC can be used as predictor of impending the septic shock.
\end{abstract}

Keywords: Septic Shock, Sepsis, ANC, Predictor Factor, Children

\section{Introduction}

Sepsis is a major problem by the patients with infections that happens in hospitalized primarily treated in children intensive care. Sepsis is a potentially life-threatening complication of an infection. Sepsis occurs when chemicals released into the bloodstream to fight the infection trigger inflammatory responses throughout the body. This inflammation can trigger a cascade of changes that can damage multiple organs systems, causing them to fail. If sepsis progresses to septic shock, blood pressure drops dramatically, which may lead to death. ${ }^{1}$ In the Faculty of Medical at the Ciptomangunkusumo Hospital in Jakarta, the incidence of sepsis in 502 patients admitted to the pediatric intensive care since January 2009 - March 2010 was 19.3\% and $43 \%$ of them had positive blood cultures. The highest incidence was in the children aged less than one year and male have a higher risk than female $(61 \% \text { vs. } 39 \%)^{2}{ }^{2}$ Sepsis is a medical emergency that needs an immediate management to reduce the deaths due to the septic shock. Septic shock caused by the circulatory failure in the presence of hypotension or hypo perfusion was settled for an hour despite an adequate fluid resuscitation given..$^{3}$ The tardiness in diagnosis and inadequate treatment caused a high mortality to incidence is still increases every year. In the United States about $10 \%$ of children with critical illness developed into septic shock. The mortality rate of the septic shock in children is $5 \%-10 \%{ }^{4}$

Most cases of septic shock caused by Gram-negative bacteria. The mediator inflammation plays an important role in the pathogenesis of inflammatory septic shock. The mediator primary shock activates neutrophils interact with the endothelial cells of the vein. The damage vascular tissue caused by degranulation of neutrophils as well as the products of free radicals produced by neutrophils. The inflammatory endothelial cell causes vasodilatation and increased the capillary permeability, causing shock. ${ }^{5}$ The effects of neutrophils in the mechanism of sepsis and septic shock can make the neutrophils as one sign of sepsis to the patient. Detecting the neutrophil activity in the laboratory using an index of the number of neutrophils can be seen by 
the Absolute Neutrophil Count (ANC). ANC is a neutrophil percentage multiplied of the total leukocytes in the blood. Its use as a prognostic indicator has been studied in a variety of circumstances, especially sepsis in the neonates and children. The increase of the ANC values correlated with the degree of sepsis to septic shock occurs and increases the risk of death. Therefore, it is important to determine the role of the ANC against the septic shock in children.

Currently, the research on the ANC in patients with sepsis is rare to be done. By looking the importance of $\mathrm{ANC}$ values in patients with septic shock and its role as a prognostic parameter, it is necessary to do a research on the ANC to patients in the emergency department. A study on ANC as a predictor factors in patients with septic shock who get into the children's emergency room in Makassar, South Sulawesi has never done; therefore, by this observational prospective cohort study, it is expected to enhance the development of clinical applications related to the outcomes of patients who get into the children emergency room. In addition, these studies also simultaneously analyze other factors that influence the ANC to the underlying disease. The purpose of this study was to determine the role of the ANC as a predictor of the occurrence of septic shock in patients who get into the children's emergency room.

\section{Materials and Method}

This was an observational prospective cohort study to assess the influence of the ANC as a predictor of septic shock in patients who get into the children's emergency room (ER). This study was conducted at the children's ER of Dr. Wahidin Sudirohusodo Hospital Makassar, starting in September December 2012 by counting the number of ANC in every incoming patient. The examination of blood samples performed in the laboratories of Dr. Wahidin Sudirohusodo
Hospital. Written informed consent was obtained from the patients' parents or legal guardian following full and detail explanation regarding the study's protocol.

The population study was all the patients who get into the children's ER with the average aged 1 month to 15 years after being treated in children's ward of Dr. Wahidin Sudirohusodo. The samples are affordable throughout the population who met the inclusion and exclusion criteria. The way of the sampling taking was the consecutive sampling, which is the subject of study are the obtained order when the patient get into the hospital. Patient who met the inclusion criteria then performed the examination number of ANC. ANC is an easy, fast inspection and did not costly because the interpretation can be seen in routine blood tests and no special skills are needed for the assessment. ANC used in this study was $1500 / \mathrm{mm}^{3}$. We divided the patients into two groups, the group of ANC $\geq 1500 / \mathrm{mm}^{3}$ and $<1500 / \mathrm{mm}^{3}$. We compared the occurrence frequency of septic shock in patients with $\mathrm{ANC} \geq 1500 / \mathrm{mm}^{3}$ and $<1500 / \mathrm{mm}^{3}$. They were observed until the occurrence of septic shock and each group was divided again into two parts, patients with septic shock and non septic shock. After that, the data are analyzed based on these risk factors with appropriate statistical method including univariate and bivariate analyses.

Determination of sample size based on desired confidence level is $95 \%$. When the proportion of the ANC change in population is $20 \%, \mathrm{RR}=1.75, \mathrm{Z} \alpha=1.96, \mathrm{Z} \beta=0.842$ and a power of $80 \%$, the total number of samples at least 65 persons. In this study, there are 110 patients; therefore, we exclude 20 patients because of malignancy, 4 patients who had received corticosteroids and 10 patients during the treatment room are forced return. Only 76 patients are left as the study sample. A total of 76 patients, 66 of them had a contagious disease (infection) and 10 of them are noninfectious.

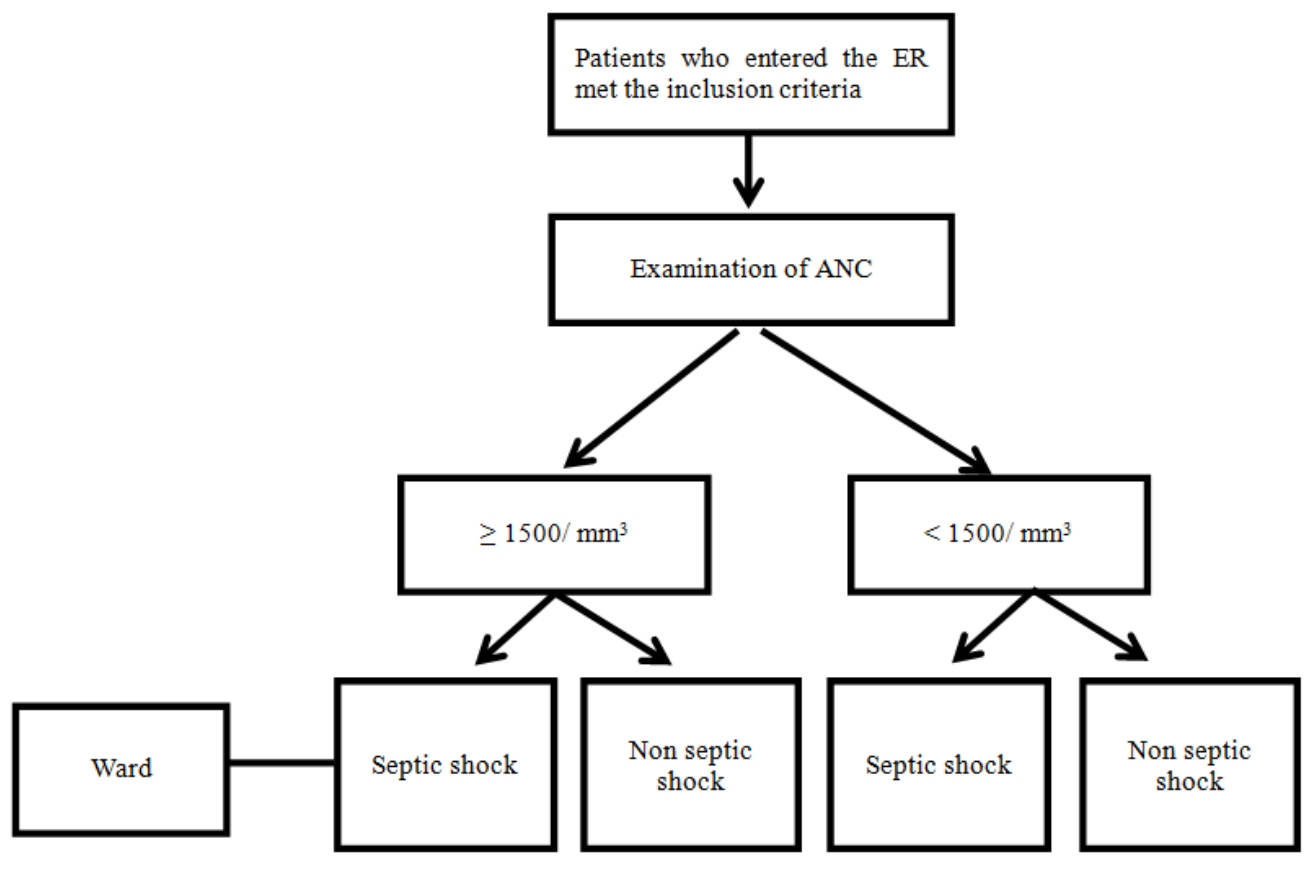

Figure 1. Study flow scheme. 


\section{Results}

Table 1 shows the characteristics of the study sample. The ANC mean of the patients in children's ER was $7575 / \mathrm{mm}^{3}$ with a minimum value of $720 / \mathrm{mm}^{3}$ and a maximum of 28570 $/ \mathrm{mm}^{3}$. The mean age of the patient's is 55 months with 1 month of age the youngest and oldest is 177 months. There were 38 males (50\%) and $38(50 \%)$ females. The distribution of the nutritional status of the most straight is respectively 43 patients of under nutrition (56.6\%), 20 well-nourished $(26.3 \%)$ and 13 with poor nutrition $(17.1 \%)$ based on the WHO parameters (patients' weight and height).

Table 1. Sample characteristics.

\begin{tabular}{llll}
\hline & $\mathbf{N}(\%)$ & Mean \pm SB & Range \\
\hline 1. Age $($ month $)$ & & $55 \pm 53.004$ & $1-177$ \\
2. ANC $\left(/ \mathrm{mm}^{3}\right)$ & $10(13.1)$ & $7575.63 \pm 5724$ & $720-28570$ \\
3. Shock & $66(86.9)$ & & \\
4. Not shock & $38(50)$ & \\
5. Sex & $38(50)$ & \\
Male & & \\
Female & $20(26.3)$ & \\
$6 . \quad$ Nutritional status & $43(56.6)$ & \\
Well & $13(17.1)$ & \\
Under & & \\
Poor &
\end{tabular}

Table 2 shows the results of the ANC in the groups of septic shock and non septic shock. The frequency of septic shock in the group of ANC $<1500 / \mathrm{mm}^{3}$ is higher than the group of ANC $\geq 1500 / \mathrm{mm}^{3}$ with respective values of $35.7 \%$ and $8.1 \%$. Statistical analysis showed significant difference with $\mathrm{p}=0.023(\mathrm{p}<0.05)$.

Table 2. ANC examination result of shock and non shock groups.

\begin{tabular}{lll}
\hline ANC $(/ \mathbf{m m 3})$ & Septic shock $(\mathbf{n}=\mathbf{1 0})$ & Non septic shock $(\mathbf{n}=\mathbf{6 6})$ \\
\hline Mean & 4551 & 8846 \\
Median & 1480 & 6650 \\
Standard deviation & 5073.6 & 8530.4 \\
Range & $720-13000$ & $1110-59585$ \\
\hline
\end{tabular}

Test Mann-Whitney U, p $=0.023(\mathrm{p}<0.05)$

Table 3 shows the relationship of the ANC with the outcome in patients who entered the child's ER. The results of the bivariate analysis showed that there were a significant differences between the two groups with $\mathrm{p}=0.015(\mathrm{p}<0.05)$. The value Odds ratio is 6.333 with $95 \%$ CI (1523-26335), the group of ANC $<1500 / \mathrm{mm}^{3}$ have 6333 times the risk of septic shock compared with a group of $\mathrm{ANC} \geq 1500 / \mathrm{mm}^{3}$. The results test of sensitivity is $50 \%$ and specificity is $86 \%$. The positive predictive value is $35.7 \%$ and the negative predictive value is $91.9 \%$.

Table 3. ANC relationship with the outcome of the patient in the Child's ER.

\begin{tabular}{llll}
\hline \multirow{2}{*}{ ANC $\left(/ \mathbf{m m}^{3}\right)$} & Septic shock & \multirow{2}{*}{ Total } \\
\cline { 2 - 3 } & Yes & No & $14(100 \%)$ \\
\hline$<1500 / \mathrm{mm}^{3}$ & $5(35.7 \%)$ & $9(64.3 \%)$ & $62(100 \%)$ \\
$\geq 1500 / \mathrm{mm}^{3}$ & $5(8.1 \%)$ & $57(81.9 \%)$ & $76(100 \%)$ \\
\hline Total & $10(13.15 \%)$ & $66(86.85 \%)$ & \\
\hline
\end{tabular}

Fisher's Exact Test, $\mathrm{p}=0.015$ ( $\mathrm{p}<0.05$ ) Odds ratio: 6.333 with IK 95\% $(1.523-26.335)$
Table 4 shows the occurrence frequency of septic shock in well nutrition at $0 \%$, under nutrition was $13.9 \%$ while the poor nutrition was $30.8 \%$. Statistical analysis showed no significant difference in the occurrence of septic shock based on nutritional status with $\mathrm{p}=0.492(\mathrm{p}>0.05)$.

Table 4. Nutritional status relationship with patients outcome treated in Children's ER.

\begin{tabular}{llll}
\hline \multirow{2}{*}{ Nutritional status } & \multicolumn{2}{l}{ Septic Shock } & \multirow{2}{*}{ Total } \\
\cline { 2 - 3 } & Yes & No & \\
\hline Well & $0(0 \%)$ & $20(100 \%)$ & $20(100 \%)$ \\
Under & $6(13.9 \%)$ & $37(86.1 \%)$ & $43(100 \%)$ \\
Poor & $4(30.8 \%)$ & $9(69.2 \%)$ & $13(100 \%)$ \\
Total & $10(13.15 \%)$ & $66(86.85 \%)$ & $76(100 \%)$ \\
\hline
\end{tabular}

Kolmogorov-Smirnov $Z=0.893, p=0.402(p>0.05)$

Table 5 shows the occurrence frequency of septic shock in male was $10.5 \%$ compared to $15.7 \%$ of female. Statistically, there was no significant difference in the occurrence of septic shock by sex with $\mathrm{p}=0.497(\mathrm{p}>0.05)$.

Table 5. Relationship of sex with the outcome of patients in ER.

\begin{tabular}{llll}
\hline \multirow{2}{*}{ Sex } & \multicolumn{2}{l}{ Septic Shock } & \multirow{2}{*}{ Total } \\
\cline { 2 - 3 } & Yes & No & $38(100 \%)$ \\
\hline Male & $4(10.5 \%)$ & $34(89.5 \%)$ & $38(100 \%)$ \\
Female & $6(15.7 \%)$ & $32(84.3 \%)$ & $76(100 \%)$ \\
Total & $10(13.5 \%)$ & $66(86.85 \%)$ & \\
\hline
\end{tabular}

Chi-Square test, $\mathrm{df}=1, \mathrm{p}=0.497(\mathrm{p}>0.05)$

\section{Discussion}

This study exclusion the malignancy because we consider that the majority of children with this disorder will show a significant decrease in neutrophils, it is consistent with the results of the research by Agodi et al. about the role of the 
ANC differentiate malignancy and arthritis in children with musculoskeletal pain, occurs decrease in neutrophils in malignancy patient $(45.5 \%)$, leukemia $(52.5 \%)$ and without malignancy $(3.3 \%) .^{6}$ The exclusion of patients with corticosteroids is also based on the consideration that corticosteroids will inhibit in neutrophil - mediated antibody - dependent cellular cytotoxity (ADCC $)^{7}$ and increases the life span of neutrophils by inhibiting apoptosis. ${ }^{8}$

The age range of the patients in this study is quite varied ranging in age from 1 month to 177 month. The age factor in this study apparently does not affect the possibility of a septic shock. The study by Watson et al., found that the age affects the epidemiology of sepsis, especially in infants under one year. Further studies on the infant population also showed that the majority (95\%) were born premature. ${ }^{9}$ Unfortunately we did not collect the data history of pregnancy and childbirth. In a population of older children and adolescents, the age factor did not significantly affect the incidence of shock. In this study, the mean age in patients with septic shock and non septic shock was over 12 months (43.90 and 37.68 months), and this could partly explain the lack of the age factor for the occurrence of septic shock.

The diseases obtained in this study consisted of a syndrome of acute nephritic, cyanotic congenital heart disease, encephalopathy, hepatic cirrhosis, and renal chronic disease. In course of their illness, patients with cirrhosis hepatic get a urinary tract infection due to catheter and then developed into the septic shock. Patients with non-infectious diseases such as post-traumatic, allergic or autoimmune can cause acute inflammation and activate mast cells, neutrophils and macrophages. The excessive activation causes endothelial damage and cytokine release proinflammatory thus have the risk of shock. SIRS can occur in patients with non-infectious before ultimately suffering the septic shock due to the acquired infection during the treatment. The study by Heffner et al. in adults was found that as many as $18 \%$ of patients with severe sepsis who were treated at the ER stems from non-infectious diseases, ${ }^{10}$ the present study, we found as many as $10 \%$ of patients with septic shock stems from non-infectious diseases, a little more higher than the proportion of the total non-infectious patients in the ER as much as $7.9 \%$.

Sex may influence the occurrence of septic shock. In adult patients the female sex has a better prognosis in the face of complications sepsis. ${ }^{11}$ In this case, progesterone serves as imunomodulator. In this study, there were no significant differences between the sexes in the occurrence of septic shock. In the child population, which has not happened hormonal fluctuations of progesterone, estrogen, and testosterone, the protective effect of progesterone has not happened.

This study showed a significant difference in the number of ANC with septic shock. Especially for the ANC group of $<1500 / \mathrm{mm}^{3}$, septic shock risk was 6.3 times greater than those of the ANC $\geq 1500 / \mathrm{mm}^{3}$. In case of sepsis, neutrophils play an important role in dealing with bacterial infections. The less number of neutrophils will cause the defense against bacteria become distracted and cause an inflammatory reaction caused by excessive bacteria and lead to the septic shock. It is different obtained by Aledo et al., ${ }^{12}$ who found no significant differences in leukemia patients with ANC $<500$ $/ \mathrm{mm}^{3}$ with ANC $500 / \mathrm{mm}^{3}-<1000 / \mathrm{mm}^{3}$ to become a septic shock.

We conclude that the mean value of the ANC in patients with septic shock is lowest than those with no experience of septic shock. The occurrence frequency of septic shock in patients with $\mathrm{ANC} \geq 1500 / \mathrm{mm}^{3}$ are lower than the patients with ANC $<1500 / \mathrm{mm}^{3}$. The amount of ANC $<1500 / \mathrm{mm}^{3}$ can be used as predictors of the occurrence factor in patients with septic shock who came into the children's ER. According to this study it can be recommended that by knowing the value of the ANC in the course of the disease into the septic shock, it is expected to consider the number of ANC in every patient who comes into the children's ER so that they can predict the course of disease in patient. If the number of ANC is $<1500 / \mathrm{mm}^{3}$, we recommended treatment and monitoring of disease faster trips more rigorous treatment of the disease in order to prevent the septic shock. Handling is good, especially on the basis of the disease is important because it can reduce the incidence of sepsis and septic shock. The result of this study can be used as a basis for further research to participate including the factors related to the patient outcome such as antibiotics and the duration of hospitalization.

\section{References}

[1] Shanle TP, Wheeler DS, Wong HS. Sepsis. Pediatric critical care medicine: basic science and clinical evidence. SpringerVerlag. London. 2007; 1424-44

[2] Yuniar I, Dewi R, Pudjiadi A. Epidemiology of pediatric sepsis in pediatric intensive care unit. FKUI-RSCM. Paediatrica Indonesiana. 2010; 50:2

[3] Goldstein B, Giroir B, Randolph A. The members of the International Consensus Conference on Pediatric Sepsis. International pediatric sepsis consensus conference: definitions for sepsis and organ dysfunction in pediatrics. Pediatr Crit Care Med. 2005; 6:2-7

[4] Cruz AT, Perry AM, Williams EA, Graf JM, Wuestner ER. Implementation of Goal Directed Therapy for Children With Suspected Sepsis in the Emergency Department. Pediatrics. 2011; 127:758-66

[5] Hotchkiss RS, Karl IE. The Pathophysiology and Treatment of Sepsis.N Engl J Med. 2003;384: 138-50

[6] Agodi A, Barchitta M, Trigilia C, Barone P, Marino S, Garozzo R, La Rosa M, et al. Neutrophil counts distinguish between malignancy and arthritis in children with musculoskeletal pain: a case-control study.BMC Pediatrics.2013;13(15):1-7

[7] Capsoni F, Meroni PL, Zocchi MR, Plebani AM, Vezio M. Effect of corticosteroids on neutrophil function: inhibition of antibody-dependent cell mediated cytotoxicity (ADCC). J Immunopharmacol. 1983; 5(3):217-30 
[8] Conrad L, Dale DC, Klebanoff SJ. Glucocorticoids Inhibit Apoptosis of Human Neutrophils. Blood Journal.1995; $86: 3181-88$

[9] Watson RS, Carcilo JA, Linde-Zwirble WT, Clermont G, Lidicker J, Angus DC. The Epidemiology of Severe Sepsis in Children in the United States.Am J Respir Crit Care Med. 2003;167(5):695-701

[10] Heffner AC, Horton JM, Marchick MR, Jones AE. Etiology of illness in patients with severe sepsis admitted to the hospital from the emergency department. Clin Infect Dis. 2010; 50(6): 814-20

[11] Schroeder J, Kahlke V, Staubach KH, Zabel P, Stuber F. Gender differ- national point-prevalence survey. J Pediatr. 2001; 39:821-7

[12] Aledo A, Heller G, Ren L, Gardner S, Dunkel I, McKay SW, Flombaum C, et al. Septicemia and septic shock in pediatric patients: 140 consecutive cases on a pediatric hematologyoncology service.J Pediatr Hemato Oncol. 1998; 20(3):215-21 